\title{
Feasibility of Three Ports Laparoscopic Cholecystectomy in Pediatric Patients
}

\author{
Pierre Jean Aurelus ${ }^{1}$, Nestor Cuauhtémoc Curiel Montano², Gabriel Terán Sánchez², \\ Roberto Carlos Ortiz Galván ${ }^{1}$, Filiberto Martínez Ramírez ${ }^{3}$ and Hermilo De La Cruz Yáñez ${ }^{1}$ \\ ${ }^{1}$ Gastro-transplantation Department, HP CMNSXXI (IMSS), México \\ ${ }^{2}$ Pediatric Surgery Department, HP CMNSXX (IMSS), México \\ ${ }^{3}$ Pediatric Anesthesia Department, HP CMNSXXI (IMSS), México \\ aurelusjean@yahoo.com.mx
}

\begin{abstract}
Introduction: The standard surgical procedure for treating benign gallbladder disease is the cholecystectomy. However there are few reports in the literature over laparoscopic cholecystectomy in pediatric population. ${ }^{1,2}$ The aim of this work was to report, retrospectively, the perioperative outcomes of this procedure to value the feasibility on three ports laparoscopic cholecystectomy in pediatric patient.

Patients and Methods: 44 consecutive patients with advanced gallbladder disease were referred in our center (HP: CMNSXXI, IMSS) for laparoscopic cholecystectomy. Data were accrued retrospectively regarding: age, gender, indications for laparoscopic cholecystectomy, peritoneal cavity access, operative time, complications, postoperative length stay and requirement to modify port number. All statistical analyses were performed using the Statistical Package for the Social Sciences version 21.0(SPSS). Significance statistical was determined at $p<0.05$.

Results: Data extracted for this review, included a total of 44 infants. From them, the mean patient age was 12.09 years (range: 2-17), male patients comprised 29.5\% $(\mathrm{n}=13)$ and female patients comprised $70.45 \%$ $(n=31)$ of all patients. Acute cholecystitis was the indication for surgical cholecystectomy in $81.8 \%(n=36)$ of the patients. The operative time had a median of $176 \mathrm{~min}$, there was no bleeding during and after the procedure, 2 patients had bile injury.

Conclusion: The three port laparoscopic cholecystectomy in pediatric population same feasible technically and the outcome of three ports laparoscopic cholecystectomy do not have increased risk of complications during and after the procedure.
\end{abstract}

KeyWords: Three Ports, Laparoscopic-Cholecystectomy, Pediatric-Patients

\section{INTRODUCTION}

Currently, the standard surgical procedure for treating benign gallbladder disease is the laparoscopic cholecystectomy; however there are few reports in the literature over pediatric population. ${ }^{1,2}$ From the first laparoscopic cholecystectomy in 1987 until the present, continuously surgeons have perfected this procedure in adult population. Actually, this is a common surgical procedure in adults and in the other hand, it is relatively uncommon in children. ${ }^{3,4}$ So many studies of different centers purposely reported the effort of surgeons group to reduce the number of port in this procedure: like it was in the Cala report, reduced the standard of four ports( Trocars) to three ports, as did Slim et al. ${ }^{1,45}$ The advantages of this procedure include decreased scarring, decreased incisional pain, shorter hospitalization and faster functional recovery, ${ }^{1,4,5}$ In fact, despite its minimally invasive nature, laparoscopic cholecystectomy frequently results in moderate to severe pain 
during the postoperative period. ${ }^{6}$ In the same sense, in attempt to reduce the morbidity and offer the benefit of laparoscopic cholecystectomy in our pediatric population, we reduced the number of four ports to three ports. Our aim was to evaluate the results of a retrospective study in the perioperative outcomes to value the feasibility on three ports laparoscopic cholecystectomy in infants. This work was performed in our pediatric center references (Hospital de Pediatría Centro Médico Nacional Siglo XXI “IMSS”/México).

\section{Patients And Methods}

Between April 2009 to December 2015, 44 consecutive patients with advanced gallbladder disease were referred in our center for laparoscopic cholecystectomy. Those procedures were performed in younger age ( $<18$ years old) by using: one $5 \mathrm{~mm}$ port and two $10-12 \mathrm{~mm}$ ports. Data were accrued retrospectively regarding: age, gender, indications for laparoscopic cholecystectomy, peritoneal cavity access, operative time, complications, postoperative length stay and requirement to modify port number. All statistical analyses were performed using the Statistical Package for the Social Sciences version 21.0(SPSS). Significance statistical was determined at $p<0.05$.

\section{Technique}

Underwent balanced general anesthesia, the patient was placed in trendelenburg position. Through an inferior umbilical incision was inserted a $10-\mathrm{mm}$ port, a $5-\mathrm{mm}$ port was inserted in the right middle-clavicular line upper the umbilical and another 10-mm port was placed in the left side in the middle clavicular line upper umbilical, figures $(1,2)$. The abdomen was insufflated to $8-10 \mathrm{mmHg}$ a $10 \mathrm{~mm}$ laparoscope was introduced, figure (3).

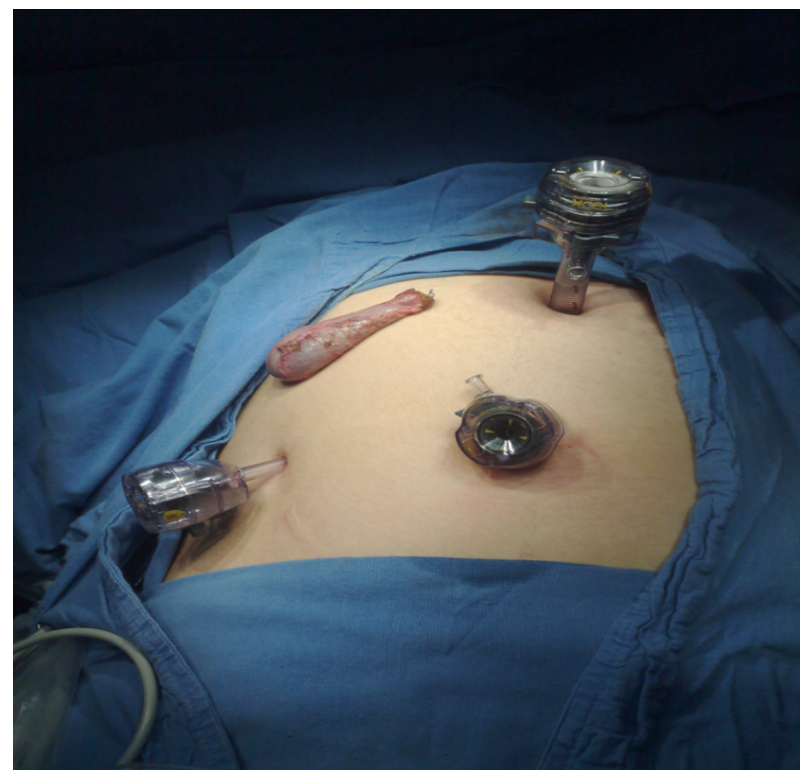

Fig1. Trocars positioning

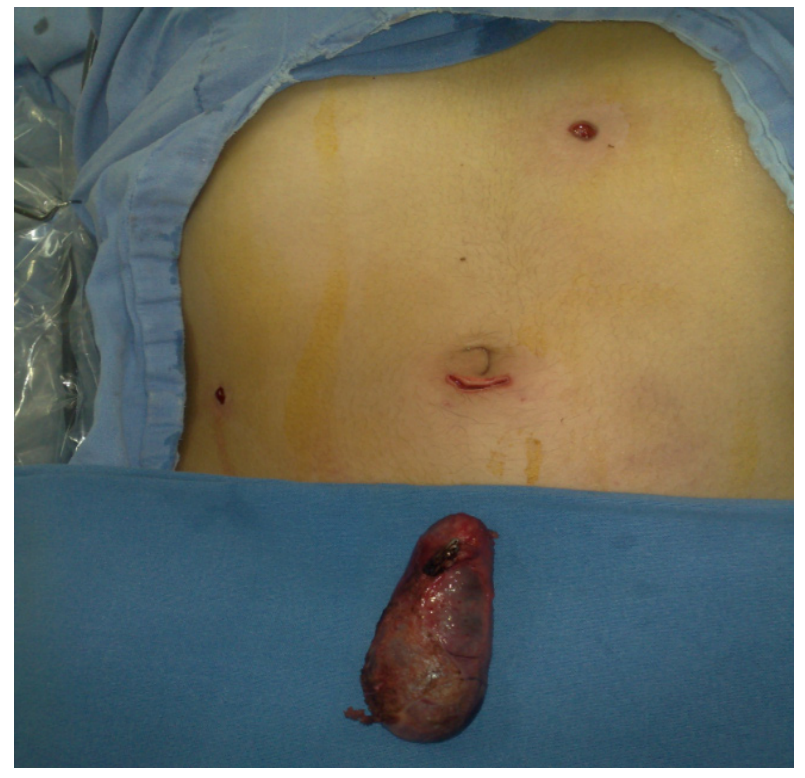

Fig2. Laparoscopic wounds procedure

The patient was rotated placed in left side position. The first step in the surgical technique was to expose Calot's triangle and isolate the cystic duct with a blunt dissection. Grasping Hartman's pouch with a 5-mm grasping double-actions forceps through the sub costal port to performed a reverse triangle and maintaining traction toward the patient's right foot, the surgeon identify the calot's triangle by dissected the hepatoduodenal ligament and the cystic duct. We placed two clips in the distal cystic and one clip in the proximal cystic duct with previous dissected and clipping the cystic artery. The gallbladder was removed by using harmonic ultrasound dissected, figure (4). 


\section{RESUlTS}

Data extracted for this review, included a total of 44 infants who underwent laparoscopic cholecystectomy during this period were subject of this study. From them, the mean patient age was 12.09 years (range: 2-17), male patients comprised 29.5\% ( $n=13)$ and female patients comprised $70.45 \%(n=31)$ of all patients. Although Acute cholecystitis was the indication for surgical cholecystectomy in $81.8 \%(\mathrm{n}=36)$ of the patients, calculous cholecystitis was in $16 \%(n=7)$ and bile dyskinesia $2.27 \%(n=1)$ of the patients. In the table 1 , we observed a summary of comparisons in patient demographic and preoperative clinical indication for the surgical procedure.

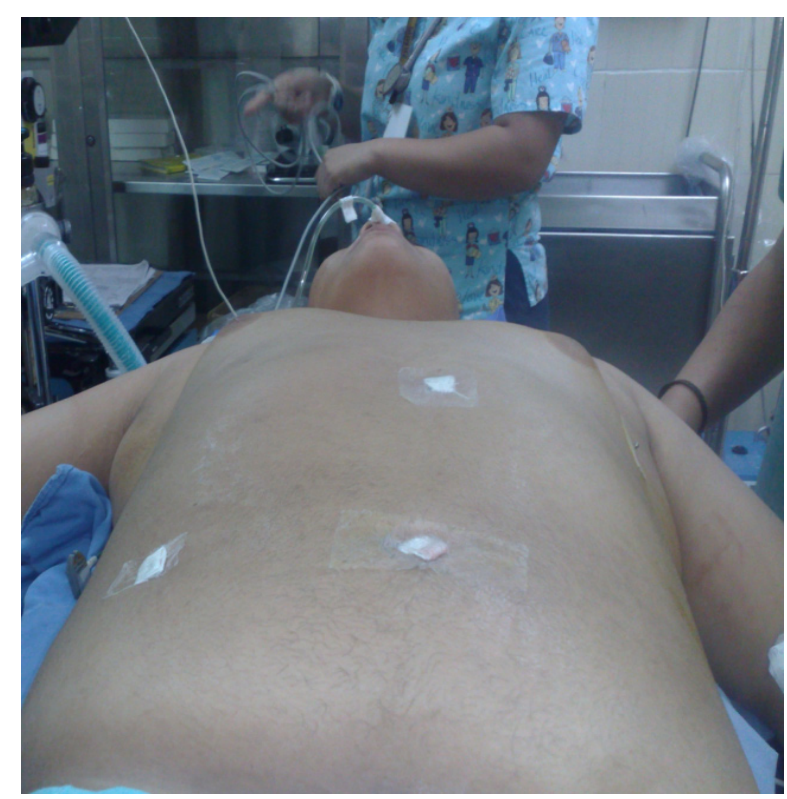

Fig3. cholecystectomy in Obesity Patient

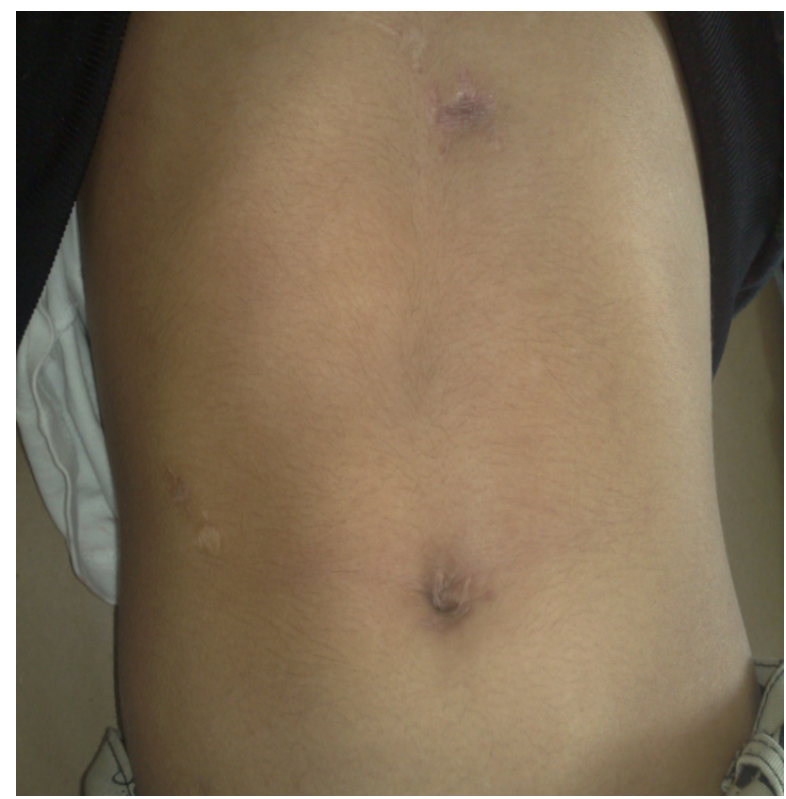

Fig4. Cosmetic aspect with three ports

Table1.

\begin{tabular}{|c|l|l|}
\hline \multicolumn{2}{|c|}{ Demographic Characteristics } \\
\hline Variable & Meeting central tendency/number & References \\
\hline Age & 12.09 & $2-17$ \\
\hline Gender & 13 & $29.5 \%$ \\
\hline -Male & 31 & $70.45 \%$ \\
\hline -Female & 51.7 & Range(11-96) \\
\hline Weight & 14 & $31.8 \%$ \\
\hline -Overweight & 10 & $22.7 \%$ \\
\hline -Obesity & \multicolumn{2}{l}{} \\
\hline Cholecystectomy indication & 36 & $81.8 \%$ \\
\hline -Biliary colic & 7 & $15.9 \%$ \\
\hline -Acute cholecystitis & 1 & $2.2 \%$ \\
\hline -Biliary dyskinesia & & \multicolumn{2}{l}{} \\
\hline
\end{tabular}

Age =years, weight=kg 
And in the table 2, we reported the complications observed during the trans-operatory and the post-operative outcomes of those patients. The operative time had a median of $176 \mathrm{~min}$, there was no bleeding during and after the procedure, 2 patients had bile injury. Abdominal pain had not severely after the operation referred with VAS Score. Two patients (bile injuries) had fever 24 hours after the performed the procedure and 42 patients were discharge at 2 days hospitalized. Two patients were performed an $Y$ by Roux and biliodigestive anastomosis secondary to bile duct injury and required more than 5 days of hospital stays. The procedure was converted in those two patients due to bile injury.

Table2.

\begin{tabular}{|l|l|l|l|}
\hline \multicolumn{4}{|c|}{ Perioperative Outcomes } \\
\hline Variable & Normal-weight (n=20) & Overweight(n=24) & $p$ \\
\hline Bile leakage & $5(25 \%)$ & $7(29.2 \%)$ & 0.047 \\
\hline Converted procedure & $1(5 \%)$ & $1(4.2 \%)$ & 0.139 \\
\hline Bile injury & $1(5 \%)$ & $1(4.2 \%)$ & 0.139 \\
\hline Cosmetic result (tolerance) & $19(95 \%)$ & $23(96 \%)$ & 0.367 \\
\hline Hospital discharge (days) & $2(+/-1)$ & $5(+/-4)$ & 0.525 \\
\hline$P$-value is significance at level & 0.001 & & \\
\hline
\end{tabular}

The length of postoperative hospitalization stay was two or single day, the incidence of intraoperative complication was $27 \%$ generally for bile leakage and $4.5 \%$ for bile injury. Postoperative complications were fever, in patients with bile injury. The high weight showed significant higher incidences of addition of another complication like bile leakage. Multiples variables were associated with prolonged operation time. Univariable analysis revealed significant association between prolonged operative time and the body mass index or the overweight.

\section{DisCUSSION}

Laparoscopic cholecystectomy is the procedure most widely used to treat symptomatic cholelithiasis; it is the most effective and minimally invasive technique in adult. Recommendation of Danish national was that patients with typical clinical sign of biliary colic should be offered cholecystectomy if gallstones were present. ${ }^{7-}$ ${ }^{10}$ Multiples studies comparing the feasibility of this procedure with four Trocars, three Trocars and the single trocar ( port). ${ }^{2,4}$ However, in pediatric population, there are few reports of laparoscopic cholecystectomy, perhaps because the frequency of cholelithiasis is a rare event in infants. ${ }^{9-11}$ In some countries, the number of cholecystectomy in children had increased over past two decades. ${ }^{3,9,10}$ The benefit of the laparoscopic cholecystectomy is to provide nearly scarless wound, reducing postoperative pain and back to normal activity so early.$^{8}$ The mean of this study was to report the feasibility of three Trocars laparoscopic cholecystectomy (LC) in children and the good outcomes regarding: postoperative pain, optimize cosmetic aspect and short hospital stays in our pediatric center.

Serious complications are associated with cholecystectomy procedure from laparotomy to minimal invasive; those complications are hemorrhage, bile duct injury, bile leakage, abdominal infection and abdominal pain. ${ }^{7}$ Indeed, many authors remain to found the adequate laparoscopic procedure by reducing the number of ports: 4 ports to 3 ports, single port and endoscopic cholecystectomy in adult population. On that purpose, our study reported the feasibility of 3 ports cholecystectomy in pediatric population. ${ }^{1,7}$ Long- term follow-up studies in adult founded that cholecystectomy is associated with an increase incidence of calculus of the common bile duct, polyps, cholecystitis, dyspepsia and colon carcinoma ${ }^{1,7,10}$ In contrast, pediatric population is different; gallbladder disease is usually observed primarily in patient with morbid conditions, such As hemolytic disorders. ${ }^{3,9,12}$ In our study the cholecystectomy indication for surgery was more frequently by biliary colic and it is more frequent in female like mentioned others reports.$^{1,10,13}$ 
Generally, the average operative time laparoscopic cholecystectomy is 170 minutes. Leggett et al reported an operative time increased from 18.5 to $20.9 \mathrm{~min}$ in cholecystectomy with 3-mm-port. ${ }^{1,2}$ Other study has reported no significant difference in operative time between 4-port and 2-port groups. ${ }^{9,14}$ In our study the operative time was $176 \mathrm{~min}$ with an average (110-293). Complications related to initial port o trocar injury reported in large series from $0 \%$ to $0.23 \%$, in our study we used Veress needle or trocar incision to gain access to the peritoneal cavity and we observed any vascular and intestinal injury., ${ }^{8,15}$ In a systematic review and meta-analysis, the pooled weight mean difference (WMD) was $1.58(0.44$ to 2.7$) \mathrm{ml}$ of blood loss, minimum in laparoscopic cholecystectomy. In our patient the intraoperative blood loss was reported $12.5 \mathrm{ml}$ in average (5-20) $\mathrm{ml}^{2,13} \mathrm{In}$ a Meta-analysis in the single-port cholecystectomy, bile injury was significantly higher than 4-port LC. In our study, 2 patients had bile injury that represented $4.5 \%$ by the total of patients. While, Lee S.C et al reported any incidence experience and conversion procedure. ${ }^{2}$

During the postoperative outcomes in this study, length of hospital stay was reported in all patients and we observed, only one of those patients included in the trial with bile injury required more hospitalization stay. S. Trastulli et al reported this outcome was $-0.10(-0.46$ to 0.26 )days in favour of single incision laparoscopic cholecystectomy (SILC) and more than 5 days in other report. ${ }^{2,3,15}$ Our length of hospital stay was 2 to 5 days generally; only in the cases of bile duct injury there was more hospitalization stay. In Esposito C study's, the surgery lasted from 25-75 min and hospital stay ranged from 1 to 10 days, in this same sense, fifteen patients required drainage. ${ }^{9,13}$ In comparison with our study, there was not required drainage in our patients although there was bile leakage during the procedure.

Referred abdominal pain intensity, VAS score founded, that it was as mild and it is known from adults that approximately $10 \%$ of the patients suffer from recurrent abdominal pain following cholecystectomy. ${ }^{2,10}$ In our wok, it is obvious the reduction of the pain intensity, only in the converted patient it was different. Various studies reports the wound infections like the S Trastulli et al that reported nine wound infections in the SILC, in our study any patient was observed with wound infection such it was to port-site hernia. ${ }^{16,{ }^{17}}$ Other important aspect, in three ports laparoscopic cholecystectomy in infant was the cosmetic result; in the body image (figure 4) there was a good aspect of the cosmetic in all patients except in the converted patient. ${ }^{17,18}$

\section{CONCLUSION}

Laparoscopic cholecystectomy is rarely performed in children. The three ports laparoscopic cholecystectomy in pediatric population same feasible technically and the outcomes of three ports laparoscopic cholecystectomy do not have increased risk of complications during and after the procedure. The postoperative stay, the duration of the procedure were very similar to those observed in four or five ports however the cosmetic aspect and the pain were better accepted in three ports laparoscopic cholecystectomy. Based in our experience, this procedure is as valid and effective as it is single or four ports laparoscopic cholecystectomy in pediatric patients.

\section{REFERENCES}

1. Leggett P.L, Bissell C.D, Churchman-Winn R, et al. Three-port microlaparoscopic cholecystectomy in 159 patients. Surg Endosc. 2001; 15: 293-96.

2. Trastulli S, Cirocchi R, Desiderio J, Guarino S, et al. Systematic review and meta-analysis of randomized clinical trials comparing single-incision versus conventional laparoscopic cholecystectomy. British Journal of Surgery. 2013; 100:191-08.

3. Sang Gyun Suh, Choi Yoo-Shin, Park Kwi-Won, et al. Pediatric Cholecystectomy for symptomatic gallstones unrelated to hematologic disorder. Ann Hepatobiliary Pancreat Surg. 2016; 20:187-90.

4. Casamassina Sacco Maria G,Gause Colin, YangJingyan, etal. Safety of outpatientlaparoscopic cholecystectomy in children: analysis of 2050 elective ACS NSQIP-pediatric cases. Pediatr Surg INT. 2016; 32: 541-51. 
Feasibility of Three Ports Laparoscopic Cholecystectomy in Pediatric Patients

5. Andolfi Vincenzo, et al. Three-port minilaparoscopic cholecystectomy in children: A single center experience. Journal of endoscopic. 2017; 5(1):1-5.

6. Sheikh Irfan Ali, Memon Ahmed Saeed, Rashid Misbath Muhammad. Three-port versus four-port laparoscopic cholecystectomy-A Two Years Experience At Combined Military Hospital Malir Cantt Karachi. Pak Armed Forces Med J. 2017; 67(2):338-42.

7. Ge Nan, Sun Siyu, Sun Shiwei, et al. Endoscopic ultrasound-assisted transmural cholecystoduodenostomy or cholecystograstrostomy as a bridge for per-oral cholecystoscopy therapy using double-flanged fully covered metal stent. BMC Gastroenterology. 2016; 16(9):1-7.

8. Comitalo Jeffrey B. Laparoscopic Cholecystectomy and Newer Techniques of Gallbladder Removal. JSLS. 2012: 16; 406-12.

9. Esposito C, Sabin González M.A, Corcione F, et al. Results and complications of laparoscopic cholecystectomy in childhood. Surg Endosc . 2001; 15: 890-92.

10. Ainswork Alan Patrick, Axelsen Anne Reiss, Rasmussen Lars. Cholecystectomy in children. Dan Med Bul. 2010; 57(11):1-3.

11. Kim Hae-Young, Kim Soo-Hong, Cho Yong-Hoon. Pediatric Cholecystectomy: Clinical of Cases Unrelated to Hematologic Disorders. Pediatr Gastroenterol Hepatol Nutr. 2015; 18(2): 115-20.

12. Wesdorp I, Bosman D, et al. Clinical presentations and predisposing factors of cholelithiasis and sludge in children. Journal of Pediatric Gastroenterology and Nutrition. 2000. 31(4): 411-17.

13. Walker Sarah K, Maki Alexandra C, Cannon Robert M, et al. Etiology an incidence of pediatric gallbladder disease. Surgery. 2013; 154(4):927-33.

14. Lee Sang Chul, Choi Byeong-Jo, Kim Say-June. Two-port cholecystectomy maintains safety and feasibility in benign gallbladder diseases: A comparative study. International Journal of Surgery. 2014; 12: 1014-19.

15. Hey Jennifer, Roberts John Keith, Morris-Stiff J. Gareth, et al. Patient views through the Keyhole: new perspectives on single-incision vs. multiport laparoscopic cholecystectomy. International HepatoPancreato-Billiary Association. 2012; 14/ 242-46.

16. Mahdi Dhaou Ben, Rahma Chtourou, Mohamed Jallouli, et al. Single-port laproscopic surgery in children: A new alternative in developing countries. Afr J Paedrtr Surg. 2015; 12(2): 122-25.

17. Iacob RE, Popiou MC, David VL, et al. Laparoscopic Cholecystectomy in Childfen-Preliminary Experience. Jurnalul Pediatrului. 2015; 71-72:38-40.

18. Mayir Burhan, Dogan Ugur, Koc Umit, et al. Safety and effectiveness of three-port laparoscopic cholecystectomy. Int J Clin Exp Med.2014; 7(8)/ 2339-42.

Citation: Pierre Jean Aurelus, Nestor Cuauhtémoc Curiel Montano, Gabriel Terán Sánchez, Roberto Carlos Ortiz Galván, Filiberto Martínez Ramírez and Hermilo De La Cruz Yáñez. "Feasibility of Three Ports Laparoscopic Cholecystectomy in Pediatric Patients". American Research Journal of Pediatrics; 1(1): 4-9.

Copyright (c) Pierre Jean Aurelus, Nestor Cuauhtémoc Curiel Montano, Gabriel Terán Sánchez, Roberto Carlos Ortiz Galván, Filiberto Martínez Ramírez and Hermilo De La Cruz Yáñez. This is an open access article distributed under the Creative Commons Attribution License, which permits unrestricted use, distribution, and reproduction in any medium, provided the original work is properly cited. 